\title{
Carcinoma de células escamosas cutâneo disseminado em bovino
}

Walter Henrique Cruz Pequeno, Igor Mariz Dantas, Francisca Maria Sousa Barbosa, Davi Amon Pereira e Souza, Jose Adriano de Lima Correia, Vanessa Rocha Amorim, Ricardo Barbosa de Lucena, Karla Campos Malta, Ruy Brayner de Oliveira Filho

Clínica de Grandes Animais, Hospital Veterinário, Centro de Ciências Agrárias, Universidade Federal da Paraíba (UFPB), Areia, PB, Brasil

*Autor correspondente

e-mail: walterpequeno@hotmail.com

\section{Resumo}

O carcinoma de células escamosas (CCE) é um neoplasma frequente nos animais de produção, sendo importante devido às perdas econômicas que acarreta. É normalmente encontrado nas junções mucocutâneas e áreas adjacentes, sendo pouco frequenteo surgimento em outras regiões. Animais com idade entre 7 e 10 anos são mais acometidos, assim como raças que possuem pelos despigmentados ou com pouco pigmento, como Holandesa, Hereford e Simmental. 0 objetivo deste trabalho é relatar um caso de CCE cutâneo disseminado em uma vaca de aproximadamente 10 anos, mestiça de raça Holandesa, com pelagem predominantemente branca, criada em sistema semi-intensivo, que foi encaminhada ao Hospital Veterinário da UFPB, Areia - PB por apresentar lesões cutâneas de crescimento progressivo há aproximadamente um ano. No exame físico observou-se que o animal apresentava-se magro e o linfonodo pré-crural direito estava aumentado de volume, firme e sem mobilidade. Lesões disseminadas com áreas de hiperqueratose e hemorragias focais foram observadas desde as orelhas e região cervical até a área de inserção da cauda, principalmente nas áreas despigmentadas. Na área do dorso estavam localizadas as maiores lesões, uma delas medindo 30 x $25 \mathrm{~cm}$ de altura. 0 animal foi contido e, após anestesia local, fragmentos de lesões da região tóraco-lombar foram retirados para avaliação histológica. $\mathrm{Na}$ avaliação histopatológica foram visualizadas múltiplas regiões em que a derme se encontrava displásica com perda da organização dos ceratinócitos, apresentando pérolas de queratina central, sendo a camada de queratina superficial da epiderme exófitica e nucleada. A derme profunda apresentava inflamação constituída de múltiplos neutrófilos e alguns linfócitos. Considerando que a ressecção cirúrgica dos neoplasmas era inviável, devido à grande extensão das lesões, foi estabelecido o prognóstico desfavorável, sendo recomendada a eutanásia. Durante realização da necropsia constatou-se que havia metástase no linfonodo pré-crural direito. 0 animal do presente relato possuía muitas áreas despigmentadas como também idade avançada, fatores que 
predispõem ao surgimento do CCE. Outro fator que deve ser considerado é a exposição frequente aos raios solares, fator carcinogênico mais importante nesta neoplasia, aos quais o bovino estava submetido em seu sistema de criação. É importante salientar que fatores genéticos influenciam na ocorrência dos CCE e que as metástases podem ocorrer em $10 \%$ dos casos, principalmente em lesões extensas ou que foram negligenciadas; ambos fatores estavam presentes e podem ter causado a metástase no linfonodo. Sendo assim, é importante ressaltar a importância de se estabelecer o diagnóstico precoce para que o tratamento possa ser viabilizado e que metástases sejam evitadas, como também evitar aquisição de animais de pelagem clara, especialmente se estes forem criados de forma extensiva no nordeste, fatores estes que devem ser considerados para evitar que os prejuízos associados a esta enfermidade continuem a acontecer. 